\title{
Integrating Geology and Engineering for Viscous Oil Production Improvement -JX Oilfield, Bohai Bay, China
}

\author{
Zhicheng Yang*, Yunpeng Li, Zongbin Liu, Gaige Wang, Qi Cheng \\ JX Oilfield, Bohai Bay, Tianjin, China \\ Email: *yangzhch7@cnooc.com.cn
}

How to cite this paper: Yang, Z.C., Li, Y.P., Liu, Z.B., Wang, G.G. and Cheng, Q. (2018) Integrating Geology and Engineering for Viscous Oil Production Improvement-JX Oilfield, Bohai Bay, China. Open Journal of Geology, 8, 859-873.

https://doi.org/10.4236/ojg.2018.89050

Received: July 11, 2018

Accepted: August 3, 2018

Published: August 6, 2018

Copyright $\odot 2018$ by authors and Scientific Research Publishing Inc. This work is licensed under the Creative Commons Attribution International License (CC BY 4.0).

http://creativecommons.org/licenses/by/4.0/

c. (i) Open Access

\begin{abstract}
In this paper a case study is presented where refined 3D reservoir geology models, well pattern pilot test and Real-time GeoSteering tools have been integrated to optimize production performance of a viscous oil reserve. The viscous reserves were of high structural dip angle. In addition delta depositional system represented highly variable geomorphology, where stacked sandbodies and shale bedding are crossing each other frequently. In order to keep a higher production rate, using horizontal wells along with water injection was not enough; therefore, detailed reservoir characterization, well pattern pilot experiment and GeoSteering were used to optimize previous development strategy and keep horizontal trajectories safely landing into reservoir target zone. The stratigraphic sequence architecture that is derived from seismic interpretations captured the variation within these high dip structural backgrounds very effectively. The best combination of choices was "Injecting Water outside from OWC" and "Stair Shaped Horizontal Trajectories". The borehole collision risks of these optimized strategies were then analyzed and controlled successfully by the GeoSteering tools during trajectory landing process. The reservoir development performance is improved tremendously as result of these renewed development strategies.
\end{abstract}

\section{Keywords}

High Viscosity Oil Development, Integration of Geology and Engineering, Horizontal Well Development, GeoSteering, Improvement of Recovery Efficiency

\section{Introduction}

The study area comprises of an oil field where 4 wells have been drilled in the second and third member of the DongYing (Ed2 3). These wells drilled were targeting the conventional front delta deposits within this strike slip basin. Well 
JX-1 was drilled in 1998 which was the first deep well targeting the reservoir; the well encountered several different reservoir sands in the upper section. Horizontal Well JX-X was drilled in 2000, targeting the reservoir. The results of both the wells were very similar, which showed that the Lower Unit is comprised of thick sand which contains several different sand units ranging from 5 to $10 \mathrm{~m}$ thickness. The spreading length of these sand bodies $(400-500 \mathrm{~m})$ is too narrow to be well controlled with this kind of well pattern.

The production results of wells were not exceptionally well, and both wells flowed 9.5 and $9.2 \mathrm{~m} / \mathrm{d}$ after which the wells depleted rapidly. Well B was drilled only $300 \mathrm{~m}$ away from Well A, but to surprise this well encountered only fractions of sand units in the Upper Unit where the thickness of sand bodies was only 2 to 5 meters much less as compared to sand thickness in Well A and B. As a result of this complex reservoir in terms of production behavior and indications of a complex depositional environment and steep structural background in this paper, a geological reservoir engineering integrated workflow was adopted along with detailed working one horizontal trajectories design to understand the full potential of this field and to determine the best location for the next development wells.

JX Oilfield is located in middle area of Liao sag, China Bohai Bay (Figure 1). The average water depth is $29 \mathrm{~m}$. Because of Tan-Lu slip faults system, it is divided into east and west parts by No.1 LiaoZhong Major fault. Furthermore, it is made up with many fault blocks which are controlled by associated faults. Controlled by this giant slip fault, western part is a simple anticline, but the eastern one is a complicated fault block trap. Both parts have a similar average dip angle between $8^{\circ}$ to $15^{\circ}$.

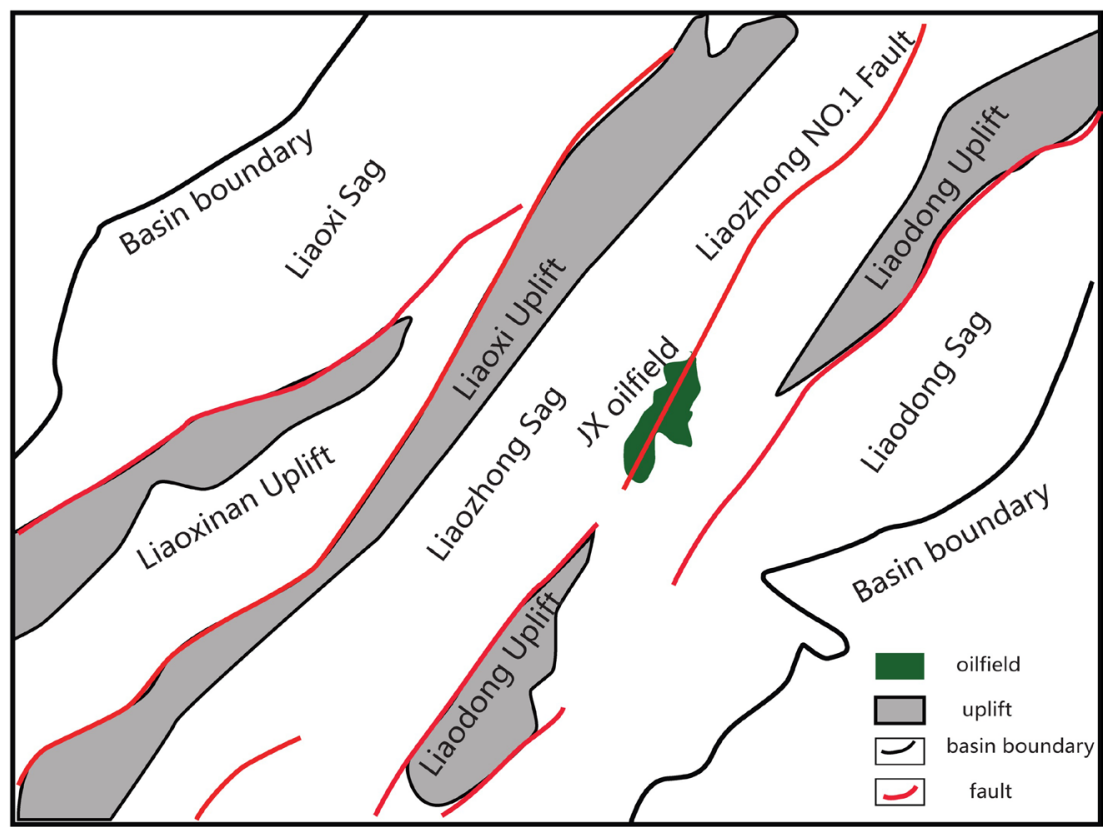

Figure 1. Location map of JX oilfield and regional structural background, target block is in south-west corner 5 block. 
Reservoir was formed during DongYin Period; sedimentary environment is consisted of meandering and braid delta. The total reservoir thickness is thick, but is separated in regular spacing shaly layers. In a map view, the reservoir shows a strip distribution pattern with width between $280-700 \mathrm{~m}$. It is a typical clastic rock consisting mid-fine and feldspar debris sand, low ingredient mature, average content of quartz is $37.2 \%$, feldspar is $39 \%$, debris is $23.8 \%$. Oil viscosity is ranging between $248.00 \sim 262.00 \mathrm{mPa} \cdot \mathrm{s}$, Formation 2 average pososity is $29.6 \%$, permeability $1431.3 \mathrm{mD}$, and Formation 3 average pososity is $26.8 \%$, permeability $893.3 \mathrm{mD}$. In general, it is a premium reservoir with high porosity and permeability but high fluid viscosity.

JX Oilfield is located in Tan-Lu slip fault band. The reservoirs have been discovered on each side of the slip fault band. West block has a lot of associated faults and strata dip is between $8^{\circ} \sim 15^{\circ}$. It is considered as layer structural trap and without a unify OWC. The maximum thickness of reservoir is $193 \mathrm{~m}$ with 8 sets of water-oil system, oil viscosity is ranging from 248 to $262 \mathrm{mPa} \cdot \mathrm{s}$. It is very difficult to make a comprehensive field development strategy for this oilfield with narrow oil area and multiple target zones. As a result, calibrated EOR only achieves $19.6 \%$ since first ODP has been executed 2008 .

The dataset for this study is summarized below:

1) $30 \mathrm{sq} \cdot \mathrm{km}$ of $3 \mathrm{D}$ seismic.

2) Openhole common logs and petrophysical analysis.

3) Production history of all wells.

\section{Objectives}

In order to further improve the understanding of the reservoir and reduce the risk of drilling, the project team has developed research objectives. The objectives of this study are summarized below:

1) To determine the stratigraphic sequence architecture of Dong 2-3 members.

2) To map the distribution channels and mouth bars based on seismic attributes and inverted impedence and to distinguish between reservoir to non-reservoir.

3) To build up a static 3D model based on the existing data which strongly integrates the dimensions of the sand bodies.

4) To choose one plan from different well optimized patterns according to the 3D model forecasting simulation results.

5) To design "stair shaped" horizontal trajectories with this 3D model.

6) To update geology understanding after optimized wells being drilled.

\section{Challenge}

\subsection{Challenge 1, Complex Structure and Reservoir Heterogeneity}

Complex slip fault background. Previous researches proved that the complex fault structural was controlled by slip faults band (Figure 2). There is an apparent 


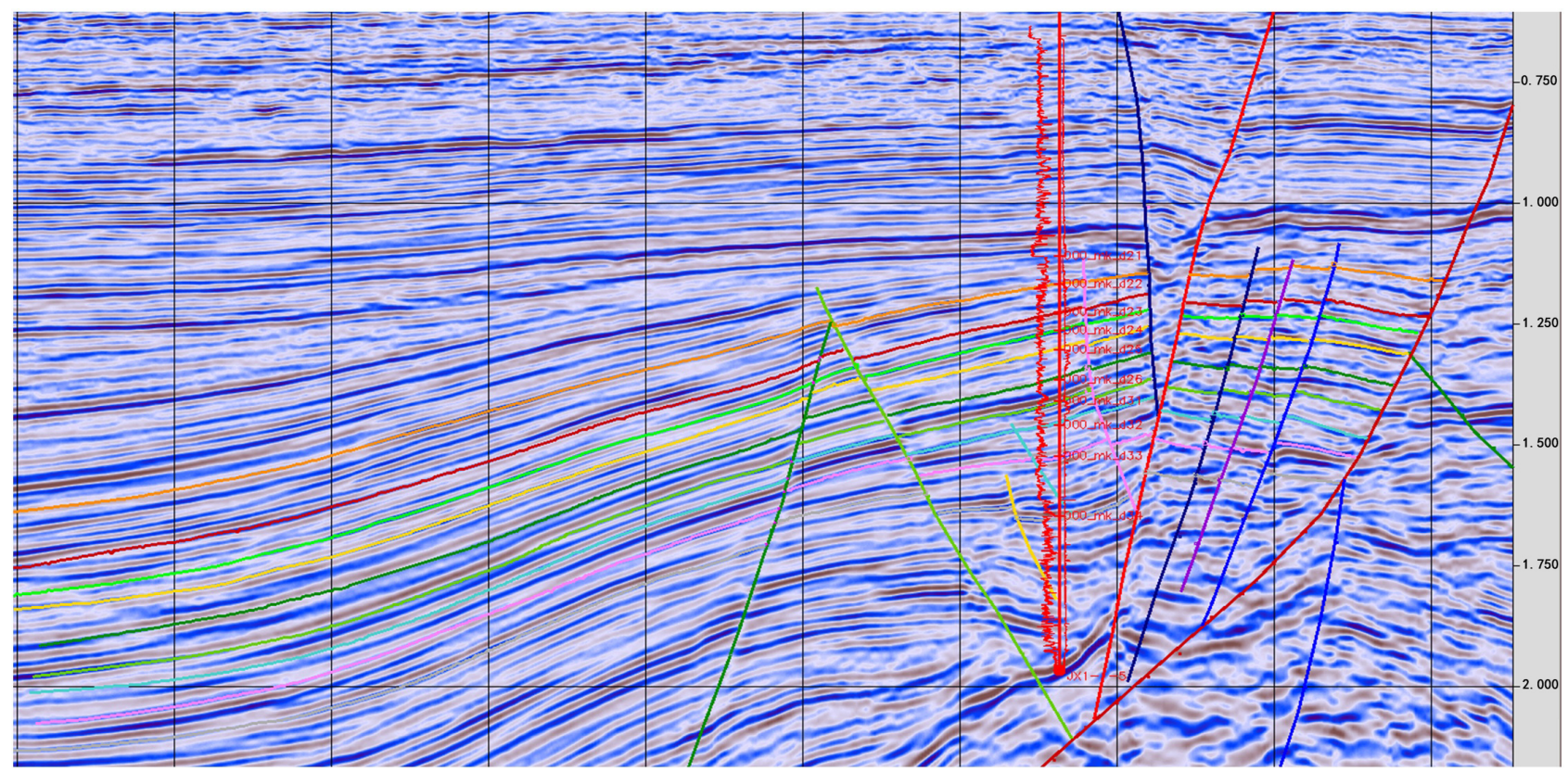

Figure 2. Flower shaped structural interpretation on a seismic section.

sag in the central part of this oilfield, which spreads from south to north directions. The biggest slip fault F1 is cutting through whole oilfield. According to seismic interpretation, there are 147 major faults of variety strikes and scales, most of the faults are 600 - 700 meters long horizontally and a "Flower" faults grouping patterns can be observed clearly in seismic sections along E-W direction. A major limitation to this reservoir is that the prediction presences a significant uncertainty to horizontal drilling design. Low seismic resolution intensifies the uncertainty. Effective band width of signal is only between $10-65 \mathrm{~Hz}$, central frequency is $35 \mathrm{~Hz}$ and average velocity is $2600 \mathrm{~m} / \mathrm{s}$ and calculated vertical resolution of this seismic cube is around $18.6 \mathrm{~m}$. However, the thickness of single sandbody is ranging from 0.2 to $16.4 \mathrm{~m}$ and average thickness is $4.2 \mathrm{~m}$ from statistical data of 5 well block. Most of single sandbody has a thickness under seismic resolution which means an integrated research is needed in this case for effectively understanding reservoir single sandbody geometry. Logging and core data shows the sand proportion along entire borehole is varying from $52.2 \%$ to $83.1 \%$, porosity $24.7 \%-34.3 \%$, Permeability $483.8-1372.7 \mathrm{mD}$, which imply that high horizontal heterogeneity and unstable intrabedding are frequently existing in this reservoir.

\subsection{Challenge 2, Unmatch between Existed Well Group Pattern and Reservoir Characteristics}

Multiple fault blocks, no unified OWC, different oil-water system, numbers of associated minor faults, high structure dip angle ( $8 \sim 15)$, narrow connected reservoir $(400 \sim 700 \mathrm{~m})$, unstable shaly interbedding (52 sets) can both affect the ODP performance of this kind of viscous oil reserve. Original ODP adopts compound pattern of "Directional Producer-Horizontal Producer-Directional 
Water Injector". This ODP includes 11 directional producers, 3 horizontal producers and 3 water injectors. The well pattern is irregular and without a fixed well space. Dong 2 member has 6 directional producers and 3 horizontal producers, with an average well space $334 \mathrm{~m}$, configure a 3:9 well group pattern; Dong 3 member has 3 directional injectors and 5 directional producers, with an average well space $460 \mathrm{~m}$. The calibrating EOR is only $19.6 \%$ in this plan.

\subsection{Challenge 3, High Drilling Risk}

Because of complex faults and low seismic cube resolution, uncertainty of the seismic interpretations is very high. Therefore, it is difficult to precisely predict reservoir top structure and adjust well path during drilling in such a high strata dip and such complex faults. Furthermore, high uncertainty of reservoir prediction results, rapid variation of surface facies and high horizontal heterogeneity can easily lead to a failure during horizontal path landing. On engineering side of view, it is also probably to happen borehole collision due to such a close distance between wells and well trajectory error cone.

\section{Solutions}

In this case with ambiguous reservoir characteristics and unmatching well group patterns, what the paper have done are compensating incapability of seismic resolution by following methods, such as seismic-well tie structural interpretation, sandbody connection analysis based on sedimentary facies, validating reservoir connection model with production observation history and finally setting up a pre-drilling geological model for horizontal wells designment. Beside these improved models, an optimized new stair shaped horizontal well development plan has been raised up and also be validated and optimized by implication of reservoir simulation software. During drilling phase, the Schlumberger GeoSteering technique was implemented to real time update pre-drilling model and adjust well trajectory.

\subsection{New Technology 1, Building up a Detailed Pre-Drilling Geomodel}

Two major difficulties on reservoir characterization exist when setting up a detailed pre-drilling geomodel. Firstly, impervious interbeddings are commonly existing inside reservoirs and separate reservoir into several sand layers, which can't be recognized from seismic section. Secondly, the existed wellbores are clustering closely, which is not easy for researchers to predict how reservoir spreads horizontally. In this situation, this paper takes following steps to do reservoir characterization. Firstly, recognize sequence boundary and divide seismic sequence by using restored pelo-topography. Secondly, making well layer correlation, which can help understand microfacies connection and stacking patterns inside architecture. Thirdly, making use of seismic attributes and inverted acoustic impedance to predict reservoir spreading inside the well correla- 
tion architecture. For example, instantaneous frequency, instantaneous phase, maximum amplitude, RMS amplitude and stochastic inversion. As a result of this integrated way, horizontal spreading distance of sandbodies thicker than 8 $m$ can be identified and correlated crossing wells [1] [2] [3].

\section{Structural Configuration of Study Area}

The main structure of the area is defined by a strike-slip basin, which is bounded by a giant strike-slip fault and several smaller faults. The main strike-slip fault is oriented in a NNE-SSW orientation with well located very close to it. This slip fault extends through the whole area. There are 147 interpreted faults in this area. As a result of strike-slip shear structural background, flower structures developed along minor restraining and releasing bends on a dextral (right-lateral) strike-slip fault can be observed clearly in the seismic sections. In addition, the dip of structure is ranging from $8-15$ degrees, which is validated by seismic-well tie interpretation. All previous researches reveal that this oilfield is a typical steep and faulted reservoir.

\section{Stratigraphic Sequence:}

Firstly, combined with the results of stratigraphic research, through the results of fine seismic interpretation, combined with the study of sequence stratigraphy, the restoration of paleo-geomorphology was carried out by using the impression method. According to three-dimensional restoration of the horizons of the strata and ZTR heavy mineral information, it shows that depositing material was transported from east-south part of whole basin. With new seismic interpretation from reprocessed seismic cube, heavy minerals and pelo-topography restoration, researches show that sedimentary material was transported from east to west. Under the interpreted fault framework, the stratigraphic sequence architecture has been set up for making up resolution incapability of seismic cube and help provide stratigraphic framework to sandbody correlations. Most importantly, the results are basic requirements to set up geological model. As a result of stratigraphic sequence division, Dong 2 section is divided into E3d2I, E3d2II, E3d2III, E3d2IV, E3d2V, E3d2VI oil formation, and Dong 3 section is divided into E3d3I, E3d3II, E3d3III (Figure 3).

\section{Stratigraphic Correlation and Facies Variation}

According to previous researches, the sedimentary environment is front delta. There are distributing channels, levee, mouth bar, beach bar, and shale five microfacies. With well logs information and kriging interpolation method, every sand thickness map of each zone has been estimated out to help identify horizontal sedimentary microfacies distribution. The stratigraphic correlation cross wells section in a NE-SW direction shows the facies variation observed on the wells from A to B. Front delta mouth bars are main microfacies in the D2 reservoir from wells section. Besides, we should also note that this section shows a number of shaly interbedding which separates the thick front delta reservoir into 4 layered shaped reservoirs. It is also important to mention here that the sand body represents a heterogeneity along different directions. The total length of 


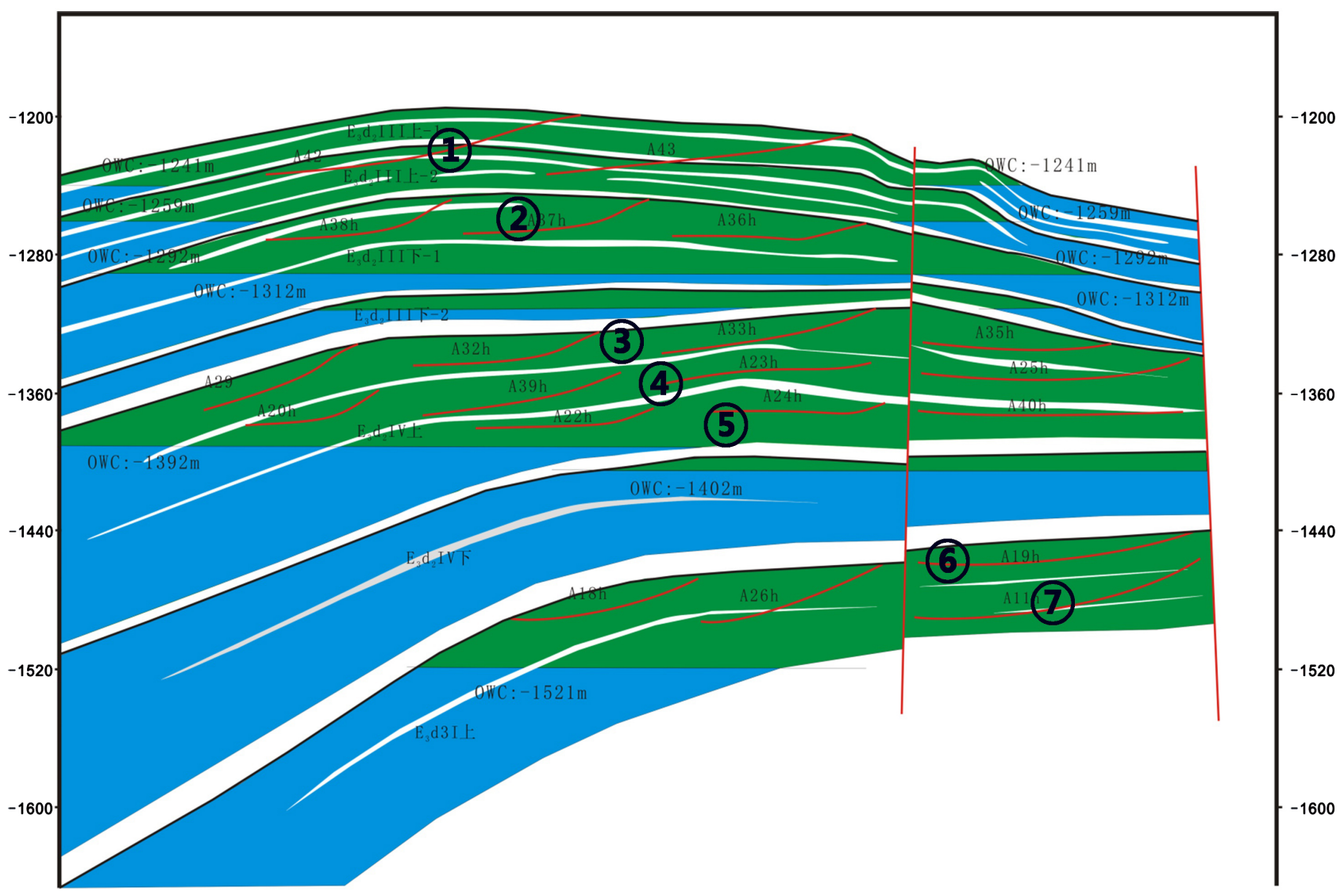

Figure 3. Detailed stratigraphic correlation framework section in No. 5 block.

connected sand bodies along paleo-depositing flowline is much longer than that in perpendicular directions.

\section{D geological model}

A complete geological model includes structural model and several property models, which can provide an integrated comprehension to pre-drilling plan and be ready for reservoir simulation. The model workflow includes: data preparation, well top correlation, structural modeling, property modeling. In this case, the stratigraphic sequence, sandbody distribution, reservoir architecture and petrophysical interpretation have been integrated to build a whole model to minimize uncertainties before drilling.

\subsection{Technology 2 Well Group Pattern Pilot Experiment}

\section{Injection Strategy Optimization}

Because of gravity, high structural dip angel $\left(5^{\circ} \sim 15^{\circ}\right)$ and high oil viscosity (248.00 $262.00 \mathrm{mPa} \cdot \mathrm{s})$ are two major factors affecting reservoir development performance, this paper sets up a theoretical equation among gravity flow, permeability, oil reserve thickness and structural dip angle four parameters to help understand how the gravity affect the development performance, which refers to the Darcy equation (Figure 4). With a simple injection and production model, the paper also has a parameter sensitivity analysis. As a result, the gravity's im- 
pact upon fluid flow should be considered when structural dip angle $>5^{\circ}$, permeability $>300 \mathrm{mD}$, oil reserve pay thickness $>10 \mathrm{~m}$. In reality, there are a great proportion of reservoir which can satisfied these requirements and the gravity impact should be considered in this situation.

$$
Q=a \frac{K h \rho g \sin \alpha}{\mu}
$$

$K$ : permeability;

$h$ : oil reserve pay thickness;

$\rho$ : density;

$g$ : gravity;

$\alpha:$ structural dip angle;

$\mu$ : water viscosity.

Different well group pattern has different development performance. In this case, reservoir simulation has been done on an updated geology model to help optimize well pattern. Four designed different well group patterns have been tested with the help of reservoir simulation, including inside injection (injector expel fluid in an early time), injection inside boundary (injecting inside oil bearing boundary), injection outside boundary (injecting outside oil bearing boundary), and injection from top (injecting from higher elevation) (Figure 5). Reservoir simulation results show injection from outside can achieve the best development performance. From previous researches, energy of present aquifer can't supply enough energy to keep a high development efficiency. Different well
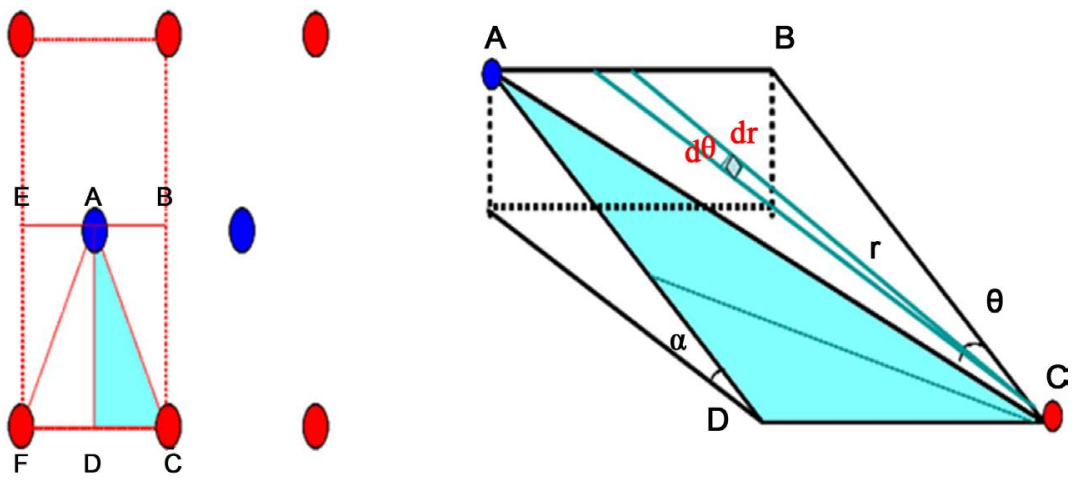

Figure 4. Corrected Darcy equation for No.5 block.
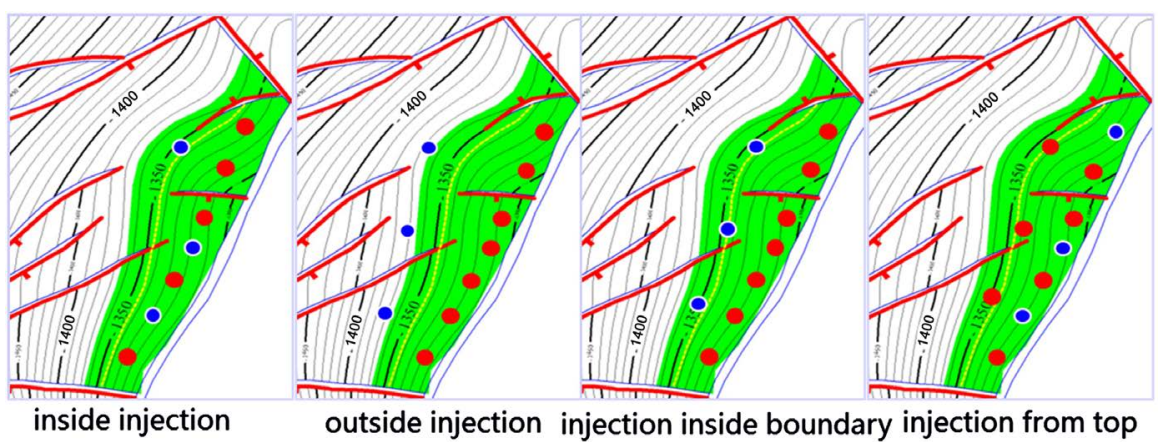

Figure 5. Well group pattern designment. 
patterns can provide different empower efficiency [4]. As a result of reservoir simulation, the injection from outside of oil bearing boundary can contribute an effective vertical "water pad" from bottom of the reservoir and optimize the relationship between water and oil in this case.

\section{Stair pattern horizontal well}

As shown before, this reservoir is divided into several individual layering zones which have different OWC. Therefore, the paper comes up with a stair horizontal well pattern which suit this reservoir better than before. This pattern can be explained from 3 aspects. Firstly, each zone with its own OWC has horizontal wells. Secondly, the horizontal trajectory direction is parallel to or intersect with structural contour with a low angle. The designed horizontal trajectory length is ranging from $250-300 \mathrm{~m}$, horizontal distance between neighboring horizontal boreholes is around $100 \mathrm{~m}$. Thirdly, Dong 2 section is divided into 3 pay zones, Dong 1 section is only 1 pay zone. Taking Dong 2 section V oil formation as an example, trajectory path geometry is designed according to $3 \mathrm{D}$ structural model, upper trajectory incline is $80^{\circ}$, middle trajectory incline is $85^{\circ}$, lower trajectory incline is $90^{\circ}$. The object of this plan is going to minimize interbedding contradictions because of reservoir heterogeneities (Figure 6).

\subsection{Technology 3, Drilling Risks Control}

\section{Well Collision Precaution}

Close horizontal trajectories spacing $(100 \mathrm{~m})$ and complex faults network lead to a high possibility of well collision. In this paper, horizontal trajectories have been designed with considerations of the integrated 3D geological model. Firstly, selecting drilling target from 3D geological model which can avoid well collision

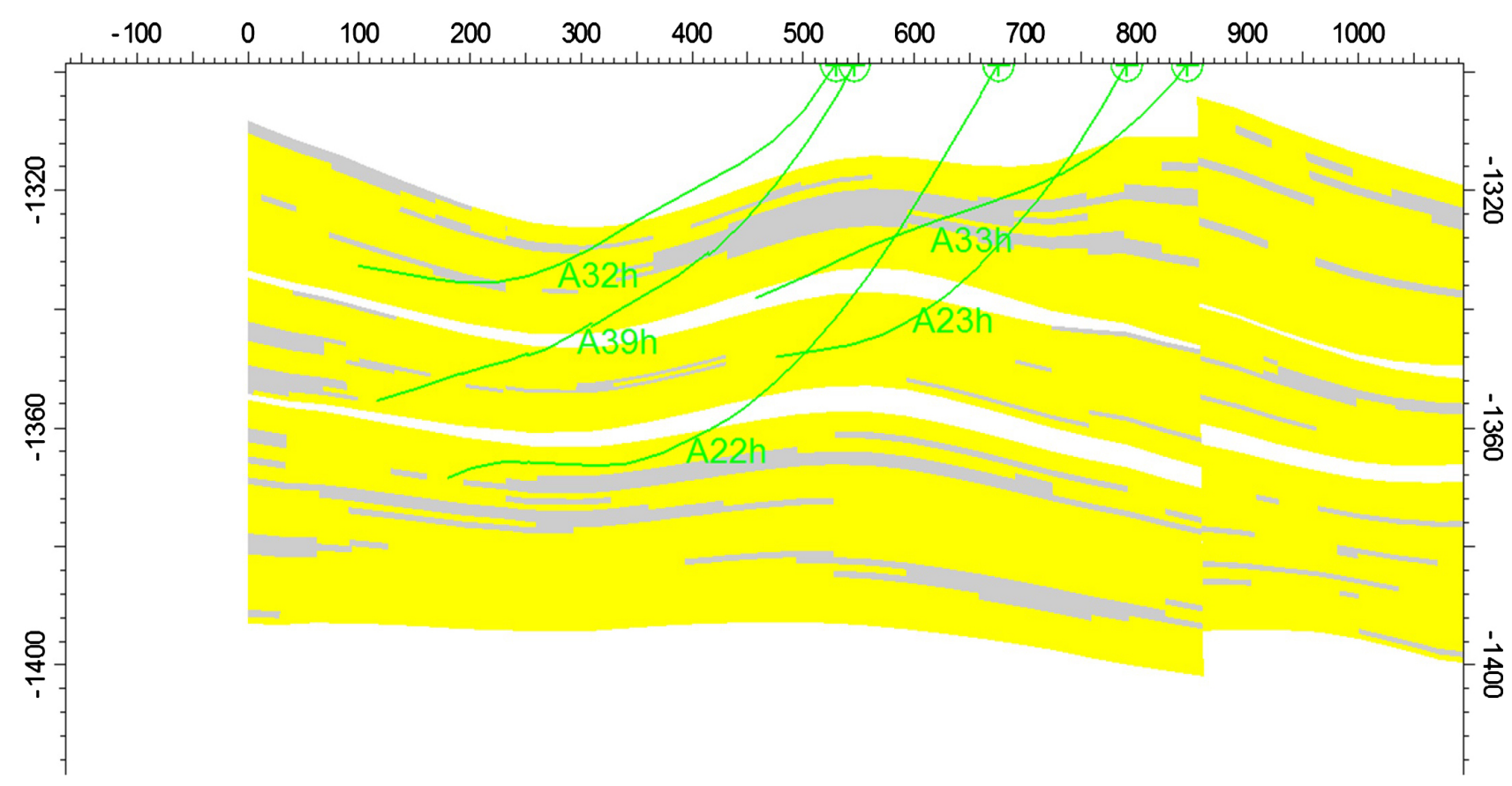

Figure 6. Stair pattern horizontal well model. 
with existing wells and keep designed trajectory right inside the oil sand bodies. Secondly, designed horizontal trajectories are following a radial pattern. Thirdly, the difference between elevation depth of KOP for neighboring horizontal wells is $30 \mathrm{~m}$. Fourthly, adding more control points onto horizontal trajectory when horizontal trajectories are very close to each other. For example, A32 and A36H, designed horizontal trajectory distance between them is $1.6 \mathrm{~m}$, but both are drilled safely and successfully by all these precautions.

\section{GeoSteering}

Setting up detailed there-dimensional model has been proved a very successful at identifying additional drilling targets, but once a drilling target had been identified, landing a horizontal trajectory within the target sand body was challenging due to uncertainty of seismic depth conversion and mapping. In JX oilfield, the oil columns are thin and the borehole collision possibility is very high. If the designed trajectory lands too shallow, it can drill within impervious zone above reservoir and the pay zone is missed. Contrary, if it lands too deep, it will stay close to the oil water contact which will lead to early water breakthrough. Neither of those scenarios are desirable for long term production outcomes. Therefore, if the wells are not landed correctly, the consequence will be a costly plug back and sidetrack. The solution to overcoming these challenges is to utilize the latest real-time drilling and formation evaluation technology so that it is possible to react in real-time to optimally land and steer the trajectory.

In current situation, sandbody boundaries can't be identified because of low resolution of seismic data. Reservoir prediction is still of a high uncertainty because of channel migration and sandbody cutting each other. The designed horizontal trajectory with pre-drilling forecast model is still of high possibility to drill into impervious zones. On the other hand, the space that driller can adjust is very limited because of consideration about well collision. Therefore, the research group decided to make use of Periscope LWD to detect potential impervious zone boundaries and get a higher proportion of reservoir along the horizontal trajectory.

GeoSteering has been proven to be an effective technique which can reduce uncertainties in well placement operations [5], including tool performance expectations, well trajectory path, geology structural and fluid contact details. The GeoSteering process is an interactive approach to well construction combining technology and people to deliver optimally placed well trajectories in a given geological setting to maximize production or injection performance. Planned interactive placement of the well-bore using geological criteria and Real-time measurements. The whole process of GeoSteering includes Directional drilling, MWD(Measure while drilling) and LWD (Logging while drilling) three parts. The LWD tools have been developed from conventional non-azimuthal tools, Azimuthal imaging tools distance to boundary tools. Nowadays, the ultra deep azimuthal electromagnetism technology, sensitive to resistivity contrasts up to tens of meters around the drillpipe, is a significant step change in the oil indus- 
try because it opens new possibilities for comparing features often observable only on seismic data. The application of this technology goes beyond traditional real-time well placement with important implications in updating 3D geological models. In JX field, the A32H1 horizontal well was drilling using Schlumberger GeoSteering Service which includes Periscope EM boundary detection LWD tools.

A successful well will remain its trajectory as possible as in the reservoir formation, whilst minimizing reservoir exits. The deep resistivity distance to boundary LWD tool was used successfully at well JX-A32H1 to ensure that wells stayed optimally positioned within the reservoir sands, as well as helping to map the extent of the sand during drilling. Furthermore, the boundaries mapped by the deep resistivity distance to boundary LWD tool helped to calibrate the seismic data and to define the top structure map. This information could also be used to re-calculate the hydrocarbon reserves as well as to improve the reservoir simulation.

An example of how the deep resistivity distance to boundary LWD tool was used at well JX-A32H1 can be seen in D2 reservoir. In an offset well penetrating this reservoir, the oil pay is thin (approximately $8-10 \mathrm{ft} t \mathrm{tv}$ ) and the Dong 3 is fairly poor quality. This leads to a low resistivity contrast between the pay sand and the overlying shale. Figure 7 illustrates the resistivity and gamma ray profiles of the Dong 2 in a nearby offset well. The low contrast between the overlying shale resistivity and oil sand resistivity can be difficult to differentiate using conventional LWD resistivity tools, however pre-job modelling indicated that

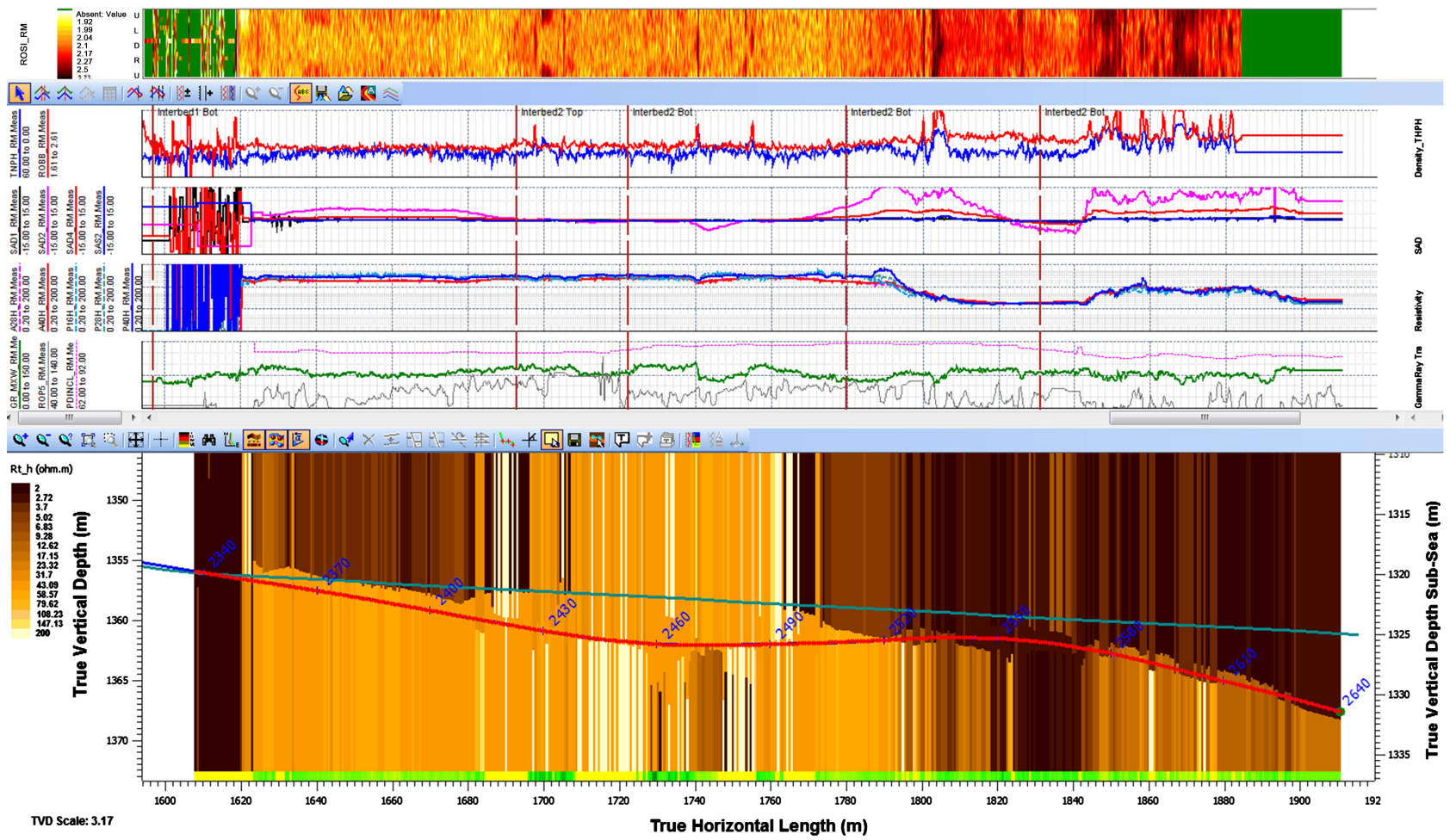

Figure 7. A32H1 ultra deep azimuthal electromagnetism inversion results. 
the deep azimuthal resisitivity tool with distance to boundary mapping could map the boundaries even in these challenging low contrast conditions. For example, $\mathrm{A} 32 \mathrm{H} 1$ is located at high part of whole reservoir. The planned horizontal trajectory will land at Dong 2 Formation. The risk of well collision is very high. Because there are other horizontal trajectories nearing this planned trajectory. In the meantime, the final trajectory is required to keep a reasonable distance to guarantee neighboring well daily production. Neighbor well is $\mathrm{A} 32 \mathrm{H}$, this well was completed in May. 2011 and had $30 \mathrm{~m}^{3} / \mathrm{d}$ oil production rate, however, it turn to a low performance well with $19 \mathrm{~m}^{3} / \mathrm{d}$, although twice acidizing works have been done. The reason why the production rate is low is that the borehole is polluted. The new $\mathrm{A} 32 \mathrm{H} 1$ is intended to help improve production around $\mathrm{A} 32 \mathrm{H}$.

A electromagnetism real-time inversion provides valuable information on the boundary distance to the wellbore which can be used to geosteer the well confidently and precisely. The distance to boundary inversion was used for the entire horizontal interval of the Well JX-A32H1 shown in Figure 7. The well, which was drilled up dip of the offset well, entered the sand at $2352 \mathrm{~m} \mathrm{MD}$ and was immediately steered down as the real time inversion indicated that the top sand was dipping down. From 2340 - 2460 m MD, the well drilled within a fairly thick good quality reservoir. Through most of this section, the top and base of the sand could be observed, with the well steered to keep the interpreted top of the sand approximately 3 - $5 \mathrm{ft}$ above the wellbore. At around $2460 \mathrm{~m} \mathrm{MD}$, it was observed that the structural dip angle was becoming flat and the well might exit the top of the sand on the current trajectory. The well was steered up and then flattened out again when it approached the center of the sand. The real-time inversion indicated that the sand continued to go up and at around $2490 \mathrm{~m}$ MD the well briefly exited the base of the sand. Around $2550 \mathrm{~m}$ (MD), the inversion result show that the target sand was going down quickly. Remarkably, the well was able to be steered within this very thin $(5 \mathrm{~m})$ sand without exiting the sand in places. This would not have been achievable using basic real-time data. In the end, the well was able to penetrate $289 \mathrm{~m}$ of good quality reservoir, whereas the original well plan would have missed most of the pay. The well was placed less than $5 \mathrm{ft}$ from the top of the sand across the entire $289 \mathrm{~m}$ leading to optimized production and delaying water breakthrough as long as possible. LWD tool was used in this drilling process and landed successfully in target zone. From the Periscope Image, the top boundary is clearly displayed from tubing toe to the end of trajectory. Due to this boundary detection tool, the total proportion of shale was effectively minimized by real time trajectory steering. By contrast, if the planned trajectory was deployed, almost most of the proportion will be landed in impervious zone. As a result, the horizontal trajectory was controlled in a distance of $10.8 \mathrm{~m}$ towards reservoir top and got a $78 \%$ sand proportion in a total $272 \mathrm{~m}$ horizontal trajectory.

$\mathrm{A} 32 \mathrm{H}$ is a horizontal oil producer which was opened in 2011. However, the production rate was relative low in the first year. In the preliminary stage, its 
pressure difference was $2.5 \mathrm{MPa}$, production rate was $19 \mathrm{~m} / \mathrm{d}$, water cut rate was $4.3 \%$. In order to improve production performance, twice acidizing works have been done but the better performance didn't last long. It was closed in Sep. 2013 and prepared for side drilling. After the $\mathrm{A} 32 \mathrm{H} 1$ has been drilled successfully with LWD tools, production rate is $40 \mathrm{~m} / \mathrm{d}$, water cut is $3.2 \%$. By contrast, the optimized well pattern gives an obvious contribution to production with integrated geomodel, optimized pilot test and GeoSteering tools.

Furthermore, a combination between LWD data and well logging of horizontal trajectory has further been used in reservoir characterization. Because planned horizontal trajectories are perpendicular to material source direction, the boundary detection data can also be used in reservoir architecture research with a combination of hydrocarbon results. Usually, the following methods can be used in reservoir geometry characterization. Firstly, LWD can provide information of reservoir thickness and horizontal spreading distance. Secondly, impervious interbeddings can be identified inside each drilled sandbody. Thirdly, the recognized interbeddings can be correlated inter wells, which is also seen as architecture boundaries (Figure 8).

\section{Performance Optimizing Analysis}

Nowadays, JX oilfield has 3 directional injectors, 23 horizontal producers. Reservoir Simulation shows the optimized well pattern can produce more $429.4 \times$ $10^{4} \mathrm{~m}^{3}$ in future 25 years, which is greater than original ODP by $143.2 \times 10^{4} \mathrm{~m}^{3}$, recovery efficient is $27.2 \%$, which has a remarkable improvement of $7.6 \%$ than before. In reality, the oil production rate was improved a lot and the water cut had been kept under $40 \%$ for 4 month after deployment of this optimized strategy (May, 2014). From a longer time of view, it can be found that the oil production

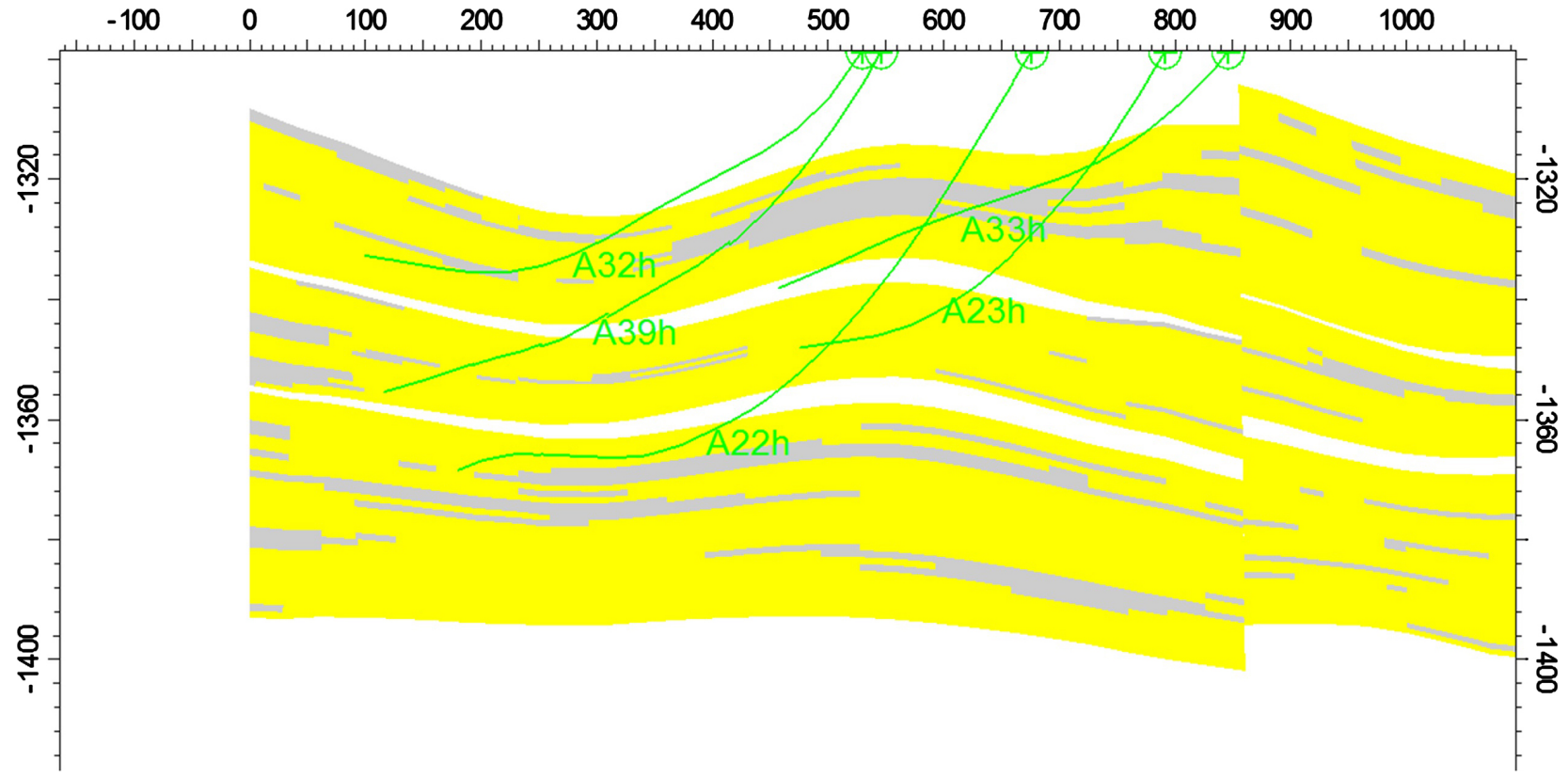

Figure 8. Updated geology understanding with new horizontal wells. 

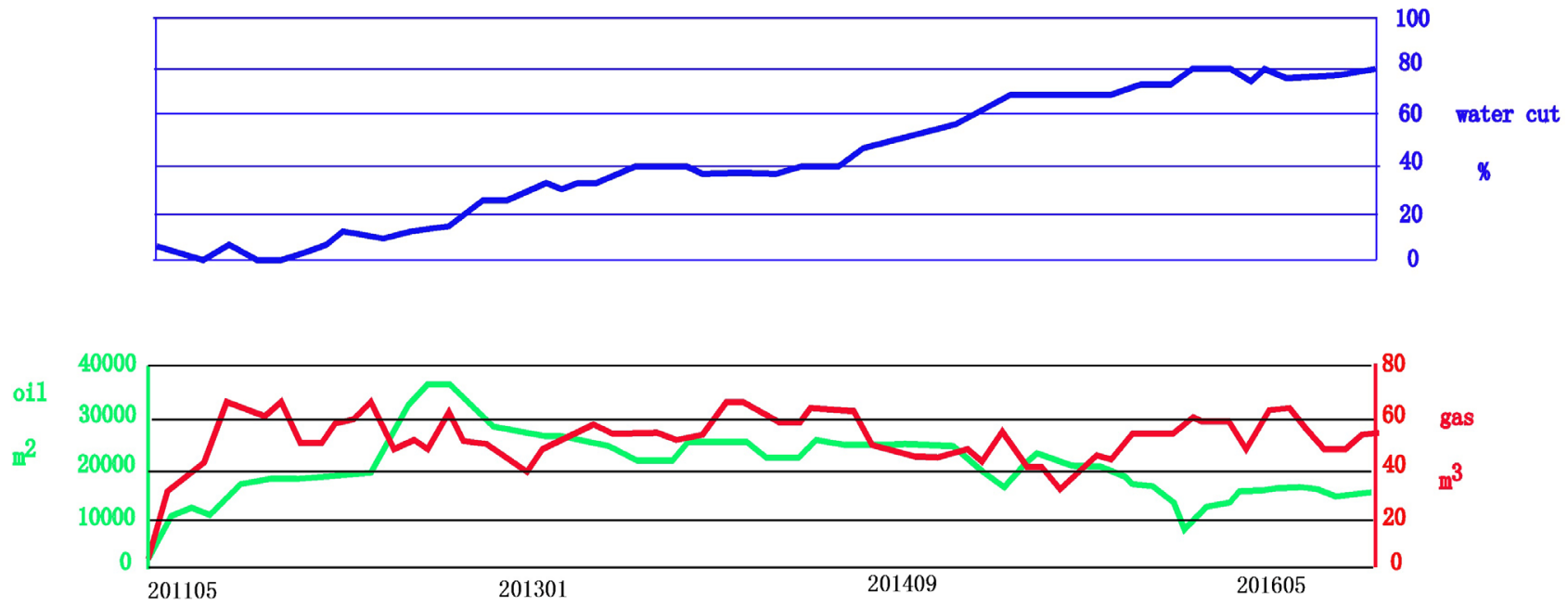

Figure 9. Observed production history after May 2011 of No. 5 block.

decreasing rate has been effectively controlled till now. Especially in 2016, there no obvious oil production decreasing in the whole year. All these information can prove that the optimized strategy takes successful effects (Figure 9).

\section{Conclusions}

This integrated solution for performance improvement in JX 1-1 No. 5 block high viscosity oil development is proved to be efficient to control production decline rate and postpone water cutting rate. The whole solution includes building up a detailed pre-drilling geomodel; well group pattern pilot experiment and drilling risks control 3 main advance technologies. Various benefits from these technology innovations include the following:

1) The integrated solution of building up a detailed pre-drilling geomodel completely incorporates geomodel and drilling design. Today's software and information advances enable multiple disciplines to refine geological model in real time to help control uncertainties.

2) Water injection plan and "stair shape horizontal wells pattern" can be easily validated by combination with geology model and reservoir simulation. Especially in this kind of unique reservoir with high viscosity and structure dip angle, there are many factors affecting development performance.

3) Ultra Deep Azimuth Electromagnetism technology can help us to land horizontal trajectories with a high drilling ratio of sandbody, which can save cost and sidetrack drilling rework.

4) Horizontal well log information can help geologist extend understanding reservoir heterogeneity in horizontal direction. Horizontal well stratigraphy correlation is a key work in integrated reservoir research after drilling works.

\section{Conflicts of Interest}

The authors declare no conflicts of interest regarding the publication of this paper. 


\section{References}

[1] Nie, C.M., Zhao, Y.S., Lv, T., et al. (2013) Development Optimization of a Marginal Oil Field in Bohai Bay, China-Integrated Solution to Overcome Challenges in Offshore Horizontal Well Construction. The International Petroleum Technology Conference, Beijing, 26-28 March 2013, IPTC 16669.

[2] Chaomin, N., Yong, J., et al. (2014) Unlocking the Potential of a Mature Heavy Oil Field Using Innovative Well Placement Technology: A Case Study from Offshore China. SPE Heavy and Extra Heavy Oil Conference, Medellín, Colombia, 24-26 September 2014, Paper SPE-171110-MS.

[3] Deng, J.M., Liu, P., Yang, B., et al. (2010) Proactive Well Placement Integrated into a Systematical Approach Enhances Productivity in a Complex Offshore Field, Bohai Bay. CPS/SPE International Oil \& Gas Conference and Exhibition, Beijing, 8-10 June 2010, SPE-131133. https://doi.org/10.2118/131133-MS

[4] Li, T.L., Ge, L.Z., Zhao, C.M., et al. (2010) Research for Horizontal Well Reasonable Drawdown Pressure of Heavy Oil Reservoir with Bottom Water. International Oil and Gas Conference and Exhibition, Beijing, 8-10 June 2010, SPE 136730. https://doi.org/10.2118/136730-MS

[5] Li, C., Hu, Y., Su, J., et al. (2015) Complex Channel Sand Development Optimization Using Advanced Technologies and a Logging-While-Drilling Measurement Application in Offshore, China. SPE/IATMI Asia Pacific Oil \& Gas Conference and Exhibition, Bali, 20-22 October 2015, SPE-176437-M0053. 